\title{
Apoio pedagógico ao ensino remoto na Universidade Federal da Fronteira Sul, Campus Chapecó
}

\author{
Elisângela Ribas ${ }^{1}$ \\ Dariane Carlesso ${ }^{2}$ \\ Rozilene Bellaver ${ }^{3}$
}

\section{RESUMO}

O Ensino Remoto tornou-se uma realidade na maioria das instituições de ensino do país no ano de 2020. O termo, até então nunca empregado, refere-se ao ensino mediado por tecnologias digitais de informação e comunicação. Trata-se de uma forma de ensino emergencial, autorizado pelo Ministério da Educação (MEC) para continuidade das aulas nas instituições enquanto durasse a situação de pandemia da COVID-19. Este trabalho caracteriza-se como um relato de experiência e tem como objetivo apresentar as medidas pedagógicas adotadas pela Universidade Federal da Fronteira Sul (UFFS), especificamente no Campus Chapecó, para a implementação do Ensino Remoto. Neste estudo, são apresentadas as diferentes ações planejadas e desenvolvidas pela equipe pedagógica, bem como as decisões institucionais que subsidiaram a oferta das aulas no período da pandemia.

Palavras-chave: Ensino remoto. Capacitações. Planejamento pedagógico. Tecnologias digitais de informação e comunicação.

\footnotetext{
${ }^{1}$ elisangela.santos@uffs.edu.br - Universidade Federal da Fronteira Sul

2 darianecarlesso@uffs.edu.br - Universidade Federal da Fronteira Sul

${ }^{3}$ rozilene.bellaver@uffs.edu.br - Universidade Federal da Fronteira Sul
} 


\section{Pedagogical support to remote education at the Federal University of Fronteira Sul, Campus Chapecó}

\section{ABSTRACT}

Remote Teaching became a reality in most Brazil educational institutions in 2020. The term, never used before, refers to education mediated by digital information and communication technologies. It is a form of emergency education, authorized by the Ministry of Education (MEC) to maintain lectures at educational institutions while the COVID-19 pandemic situation remains. This work is characterized as an experience report, and it presents the pedagogical measures adopted by the Federal University of Fronteira Sul (UFFS), specifically at Campus Chapecó, for the implementation of Remote Teaching. The different actions planned and developed by the pedagogical team are presented, as well as the institutional decisions that supported the offer of classes during the pandemic period.

Keywords: Remote teaching. Training. Pedagogical planning. Digital information and communication technologies. 


\section{INTRODUÇÃO}

A pandemia da COVID-19 assolou o mundo em 2020 e mais precisamente o Brasil a partir de março desse mesmo ano, fato que resultou na suspensão de atividades nas mais diversas áreas, em especial nas instituições de ensino. Diante do cenário preocupante e do aumento exponencial do nível de contágio da COVID-19, diversas medidas de segurança foram adotadas pelos governos estaduais e municipais, com intuito de, entre outras questões, evitar aglomerações e proteger as pessoas dos riscos de contágio. Na esfera federal, o Ministério da Educação (MEC) suspendeu as aulas presenciais em todas as instituições de ensino do país.

Para as instituições de Educação Superior, a Portaria 343, de 17 de março de 2020, apresentou a possibilidade de substituição das aulas presenciais por aulas em meios digitais enquanto durasse a situação pandêmica (BRASIL, 2020a). A Portaria previu a suspensão pelo período de 30 dias, mas passado tal período e diante do contínuo aumento de contágio do vírus em todo território nacional, nova Portaria foi expedida, $\mathrm{n}^{\circ} 544$, estendendo o prazo de suspensão de atividades presenciais para 31 de dezembro de 2020 (BRASIL, 2020b).

Diante do cenário nacional, as instituições de educação do sistema federal de ensino do Brasil começaram a se organizar para que as aulas que, até então, eram ministradas majoritariamente de forma presencial, passassem a ser desenvolvidas por meios digitais. Nesse sentido, este artigo tem como objetivo apresentar as medidas pedagógicas adotadas pela Universidade Federal da Fronteira Sul (UFFS), especificamente no Campus Chapecó, para implementação das aulas mediadas por tecnologias, o que, para fins desta publicação, serão denominadas como Ensino Remoto, mesma nomenclatura adotada pela UFFS em seus documentos oficiais.

As Portarias expedidas pelo Ministério da Educação que abordaram a suspensão das aulas presenciais nas instituições de Ensino Superior, autorizaram aulas em meio digital. Apesar disso, é importante ressaltar que o Conselho Nacional de Educação (CNE), quando expediu o Parecer CNE/ CP 5/2020, o qual abordou a reorganização do calendário escolar, utilizou a expressão "atividades pedagógicas não presenciais", assim como "atividades pedagógicas remotas". Os termos empregados pelo CNE consideraram que as aulas poderiam ocorrer de forma não presencial e não especificaram a necessidade do uso de tecnologias digitais, em função de que muitos estudantes e professores não possuíam, assim como ainda não possuem, acesso a tecnologias digitais (BRASIL, 2020c).

Considerando os aspectos mencionados até o momento, este texto apresenta um relato de experiência que em seu desenvolvimento situa o contexto histórico da criação da UFFS; em seguida, indica as medidas adotadas para conhecer a realidade de acesso a tecnologias por parte dos estudantes a fim de mapear a formação e competência tecnológica dos professores; e, por fim, apresenta as possibilidades pedagógicas oferecidas a professores e estudantes para que pudessem realizar as aulas de forma remota com o uso de tecnologias digitais. 


\subsection{Histórico da UFFS e uso de tecnologias digitais aplicadas ao ensino}

A UFFS foi criada no ano de 2009, por meio da Lei 12.029 (BRASIL, 2009), possui 6 campi, com abrangência nos Estados do Paraná, Santa Catarina e Rio Grande do Sul, em regiões historicamente desassistidas de Ensino Superior público e gratuito. A instituição iniciou suas atividades de ensino em março de 2010, com cursos $100 \%$ presenciais e, na sua maior parte, cursos de licenciatura.

Na medida em que iniciava suas atividades, a instituição também constituía seus órgãos deliberativos e regramentos sobre o funcionamento da instituição. O Regulamento de Graduação, importante balizador das atividades de ensino na instituição, foi um dos primeiros a ser debatido e consolidado, em que pese ter sofrido alguns ajustes com o passar dos anos, não abordou de forma profunda as possibilidades dos usos de mídias para uma educação não presencial, por exemplo. Do mesmo modo, nos processos de criação de novos cursos pela instituição, a oferta presencial sempre foi a tônica dos percursos formativos apresentados e aprovados.

Apenas no ano de 2014, por força da já existente Portaria MEC nº 4.059 de 2004 (BRASIL, 2004), a UFFS regra internamente as possibilidades de oferta de componentes curriculares no formato semipresencial, sem ultrapassar $20 \%$ da carga horária total dos cursos de graduação. A partir de então, de maneira muito tímida, à luz da Resolução 5/2014 - CONSUNI/Câmara de Graduação (UFFS, 2014), alguns cursos passaram a inserir percentuais muito pequenos de ensino não presencial em seus currículos, quando dos processos de reformulação curricular, após o protocolo de Reconhecimento dos Cursos pelo MEC.

Embora hoje o requisito do Reconhecimento do Curso não esteja mais vigente, de acordo com a Portaria MEC n².117, de 2019 (BRASIL, 2019), e a carga horária passível de ser realizada a distância possa chegar até $40 \%$ da carga horária total dos cursos, mesmo assim, a UFFS tem uma experiência muito incipiente sobre as atividades a distância. Os percentuais, nesse formato de ensino, nos cursos são baixíssimos ou inexistentes.

A falta de experiência da educação não presencial, seja por opção política institucional ou por concepção individual dos docentes, razões legítimas, contribuiu para um impacto significativo sobre os modos de fazer decorrentes do Ensino Remoto. Conforme apresentado a seguir, muitos foram e são os desafios postos pela condição de realizar as atividades acadêmicas mediadas essencialmente pelas mídias e tecnologias da informação.

\subsection{Tomada de decisão sobre aulas mediadas por tecnologias digitais: Ensino Remoto}

Aulas mediadas pelas Tecnologias Digitais de Informação e Comunicação (TDIC) são uma realidade no Brasil em diferentes instituições de ensino. Mesmo que não haja uma adesão massiva por parte dos professores ou que essa adesão não perpasse os projetos pedagógicos 
institucionais, fazer ou não uso de TDIC para o processo de ensino e aprendizagem é, antes de tudo, uma decisão pedagógica e metodológica de cada professor. Ainda que com poucas ofertas de componentes curriculares semipresenciais, a UFFS ainda não concentrava, até o ano de 2020, expressivas práticas formativas institucionais e periódicas aos professores que os habilitassem a fazer uso de tecnologias e metodologias para ministração de aulas por meios digitais. Fato que não contribuiu ao longo da história da universidade para incentivar novas adesões à oferta de componentes curriculares semipresenciais ou ofertas de cursos de extensão ou graduação a distância. Dessa forma, a implementação do Ensino Remoto 4 no período de pandemia gerou muita discussão e resistência tanto por parte dos estudantes como dos professores. Afinal, o ano letivo de 2020 estava planejado para ser presencial e havia expectativa inicial de que as aulas presenciais pudessem ser retomadas até junho do mesmo ano; contudo, isso não foi possível em função de que a pandemia foi mais duradoura do que se imaginava inicialmente.

Em abril de 2020, quando o assunto do Ensino Remoto ainda era grande novidade entre os estudantes e servidores, os conselheiros do Conselho Universitário (Consuni) definiram, em reunião, a constituição de um grupo de trabalho para a realização de um mapeamento junto aos estudantes e professores, com objetivo de identificar as condições de acesso dos discentes e as habilidades dos docentes em manusear diferentes tecnologias digitais para ministração de aulas remotas. Além disso, deveriam ser mapeados os recursos institucionais disponíveis para criação e realização das aulas. Para tanto, foi criada uma comissão institucional com 13 servidores entre técnicos-administrativos e professores, representantes dos diferentes campi da UFFS, bem como das diferentes pró-reitorias.

O relatório produzido pela referida comissão apontou, dentre outras questões, os sistemas de informática mais indicados para criação e desenvolvimento de aulas virtuais. Os sistemas para videoconferência, ou seja, para desenvolvimento de aulas síncronas, foram o Webex Meeting e Training. Já o Moodle foi indicado para que fosse utilizado como sistema de gerenciamento da aprendizagem. Cabe ressaltar que, embora a instituição não ofereça cursos na modalidade a distância, o Moodle é o ambiente virtual de ensino e aprendizagem utilizado pela UFFS há muitos anos ,seja como apoio ao Ensino Presencial, seja para apoio aos processos de gestão da universidade.

Para mapear as questões ligadas aos estudantes, foi criado um instrumento com diferentes questões. A divulgação do instrumento foi realizada pelo e-mail dos estudantes, em redes sociais da instituição e no site institucional. Do total de 8.431 matriculados em algum curso de graduação da UFFS em abril de 2020, responderam ao questionário aplicado 4.414 estudantes, o que resultou na abrangência de 52,29\% dos alunos com matrícula ativa. Entre as diversas questões que integraram o referido instrumento, há destaque para aquelas que buscaram conhecer o tipo de conexão à internet que o estudante possuía. Cabe ressaltar que $1,40 \%$ dos respondentes afirmaram não ter acesso à internet. Para $27,39 \%$ dos estudantes, o celular era o único meio de acesso à internet, enquanto que o restante, $71,10 \%$, possuía um

\footnotetext{
${ }^{4}$ Por Ensino Remoto entende-se o tipo de ensino emergencial adotado pelas instituições de ensino, a partir da autorização do Ministério da Educação, para desenvolvimento das aulas no período de pandemia do novo coronavírus.
} 
computador para acessar a internet. Daqueles que mencionaram ter acesso à internet, $66,27 \%$ indicaram que seu tipo de acesso era exclusivo, enquanto 32,33\% dos estudantes mencionaram que dividiam seu acesso com outras pessoas. Quando questionados se sabiam manusear diferentes tecnologias para realização de aulas virtuais, 38,51\% informaram que precisariam de algum tipo de auxílio com o Ensino Remoto.

A fim de compreender a realidade dos docentes, foi construído um instrumento, com diversas questões, e enviado por e-mail a todos os professores em exercício na universidade, fossem eles efetivos ou substitutos. Em abril de 2020, o número total de professores na UFFS era de 767 , dos quais 428 responderam ao instrumento aplicado. Desse total, $88,58 \%$ informaram que nunca tinha realizado alguma das formações sobre Tecnologias na Educação ofertadas pela UFFS. Quando questionados se conheciam metodologias e tecnologias para aulas a distância, 9,59\% dos respondentes informaram que as conheciam. E, com relação à última questão apresentada, que buscou conhecer se o professor se sentia em condições de ministrar algum componente curricular com uso de tecnologias digitais, ou seja, de forma remota, $21 \%$ informaram que sim. O questionário integrou outras questões similares que buscaram conhecer mais se o professor conhecia diferentes softwares e hardwares que poderiam ser utilizados para construção de aulas virtuais.

O relatório foi apresentado aos conselheiros do Consuni que não entraram em consenso sobre a retomada geral das atividades acadêmicas de forma não presencial. Os impasses giravam em torno dos acessos aos estudantes às tecnologias e às condições de produção e ministração de aulas por meios digitais. Ainda nesse momento, em abril, não se tinha certeza sobre as possibilidades de retorno ao presencial, mas a expectativa era de que seria algo iminente. Isso não se evidenciou, porém, nos meses vindouros, e, em agosto de 2020, houve o planejamento de diferentes possibilidades de retomada das aulas, o que resultou em algumas versões do calendário acadêmico. Tais versões, quando apresentadas ao Consuni, viabilizaram a tomada de decisão a respeito do retorno das atividades acadêmicas para o mês de setembro de 2020, de forma remota, em todos os cursos de graduação da UFFS.

\subsection{Iniciativas do Núcleo de Apoio Pedagógico do Campus Chapecó}

Na UFFS, cada campus possui seu Núcleo de Apoio Pedagógico (NAP), composto por uma comissão eleita pelos servidores, da qual participam professores e técnicos administrativos em educação. Instituídos por resolução própria, os NAPs fazem a interlocução entre a Coordenação Acadêmica do seu campus e a Pró-Reitoria de Graduação. A Resolução nº 13 (UFFS, 2013), que institui os NAPs em cada campus, apresenta os seguintes objetivos: (i) fomentar o debate político-pedagógico no Campus; (ii) promover a formação continuada dos professores, visando o aperfeiçoamento didático-pedagógico por meio de cursos e eventos que auxiliem na qualificação da prática docente; (iii) proporcionar apoio pedagógico a partir de necessidades apontadas nos diversos setores do Campus .

Tendo em vista os objetivos listados, os quais reforçam a necessidade de que o NAP atue diretamente no apoio pedagógico a partir de necessidades emergentes, os membros do NAP Campus Chapecó (NAP-CH) tomaram a decisão de construir um planejamento pedagógico com 
ações que visassem apoiar os professores no planejamento e desenvolvimento de aulas remotas. As ações foram: (i) guia de ensino com informações sobre planejamento e produção de materiais didáticos virtuais; (ii) ciclo de webconferências sobre o Ensino Remoto; e (iii) orientações acerca do planejamento, registro e desenvolvimento de aulas a partir das regulações internas da universidade.

A primeira ação foi a construção de um site, chamado de Guia de Ensino, com orientações acerca da produção de aulas virtuais. $O$ site apresentou diferentes informações sobre a criação de conteúdos, tanto textuais como audiovisuais, criação de atividades para a virtualidade, informações sobre direitos de uso, recomendações de repositórios de objetos educacionais, sugestões de ferramentas para criação de recursos didáticos, entre outros materiais que poderiam contribuir para o desenvolvimento de aulas virtuais.

Logo em seguida, houve a criação do Ciclo de Webconferências sobre Ensino Remoto que integrou o planejamento de diferentes formações virtuais. As formações foram abertas à comunidade em geral; contudo, algumas delas tratavam de questões da própria universidade. Os temas abordados no Ciclo de Webconferência foram: (i) criação de conteúdos; (ii) construção de atividades; (iii) produção de videoaulas; (iv) qualidade em aulas virtuais; (v) avaliação no ensino remoto; (vi) gamificação; (vii) diálogo sobre o ensino remoto e (viii) retorno do semestre letivo, vamos acolher os estudantes? A fim de viabilizar as formações e de concentrá-las em um único local, foi criado um canal no YouTube, que também poderia ser acessado pelo site, Guia de Ensino, do NAP-CH.

Além das ações descritas, houve produção de orientações em formato textual, enviadas a todos os professores do Campus Chapecó. As orientações versaram sobre planejamento, construção de planos de ensino tendo em vista o Ensino Remoto, avaliação da aprendizagem em ambientes virtuais, cômputo de frequência considerando aulas síncronas e assíncronas, entre outros. Por fim e não menos importante, os membros do NAP-CH se dispuseram a participar das reuniões de colegiados de curso a fim de que pudessem realizar esclarecimentos e contribuir no debate pedagógico emergente.

\subsubsection{Iniciativas do Núcleo de Apoio Pedagógico do Campus Chapecó}

Tendo em vista a emergência dos assuntos ligados ao Ensino Remoto, os membros do NAP-CH resolveram implementar ainda em julho de 2020, quando não havia certeza sobre a retomada do calendário acadêmico na UFFS, o $1^{\circ}$ Ciclo de Webconferências sobre o Ensino Remoto. A tomada de decisão, mesmo sem ter previsão do início das aulas e se essas seriam de forma remota, foi realizada em função de que quanto mais tempo dispusessem e mais informações sobre a produção de aulas virtuais os professores conseguissem obter, maior qualidade poderiam aferir as suas produções.

Depois de ocorrido o planejamento das temáticas e realizados os convites aos ministrantes - todos servidores de alguma instituição federal de ensino do país - foi o momento de divulgar as formações. Todas foram organizadas no sistema Webex e transmitidas no YouTube a partir do software OBS. Para apoiar as transmissões, foi realizada uma parceria com o Programa de Ampliação e Consolidação de Tecnologias e Inovação no Contexto Educacional 
(Practice), implementado na UFFS ainda em 2020. Com essa parceria, os bolsistas do Practice ficaram incumbidos de realizar as transmissões no YouTube e os membros do NAP se responsabilizaram pela mediação nas formações, gerenciamento das perguntas no chat do YouTube, divulgação dos links para inscrições e avaliação do evento, para acompanhar as formações de forma geral e identificar possíveis erros ou contratempos que pudessem surgir.

A inscrição nos eventos não foi obrigatória, mas garantia a obtenção de certificado de participação. Nos 8 eventos realizados, o total de pessoas inscritas foi de 598. Além da inscrição, foi disponibilizada uma ferramenta para avaliação do evento, que também era optativa aos participantes, realizada por meio do site Slido, para realização de enquetes. A cada evento, era disponibilizado o link para avaliação da formação que estava sendo transmitida. Os participantes poderiam informar uma nota em uma escala de 0 a 5 , quanto maior a nota atribuída, maior o grau de satisfação do participante com a formação assistida. A média geral das 8 formações foi de 4,8 pontos.

Como já mencionado, as formações foram transmitidas diretamente no YouTube e por isso foi possível acompanhar as estatísticas de visualizações. A Figura 1 apresenta os dados completos para cada vídeo transmitido no canal.

\section{Figura 1 - Estatísticas do Canal do Núcleo de Apoio Pedagógico}

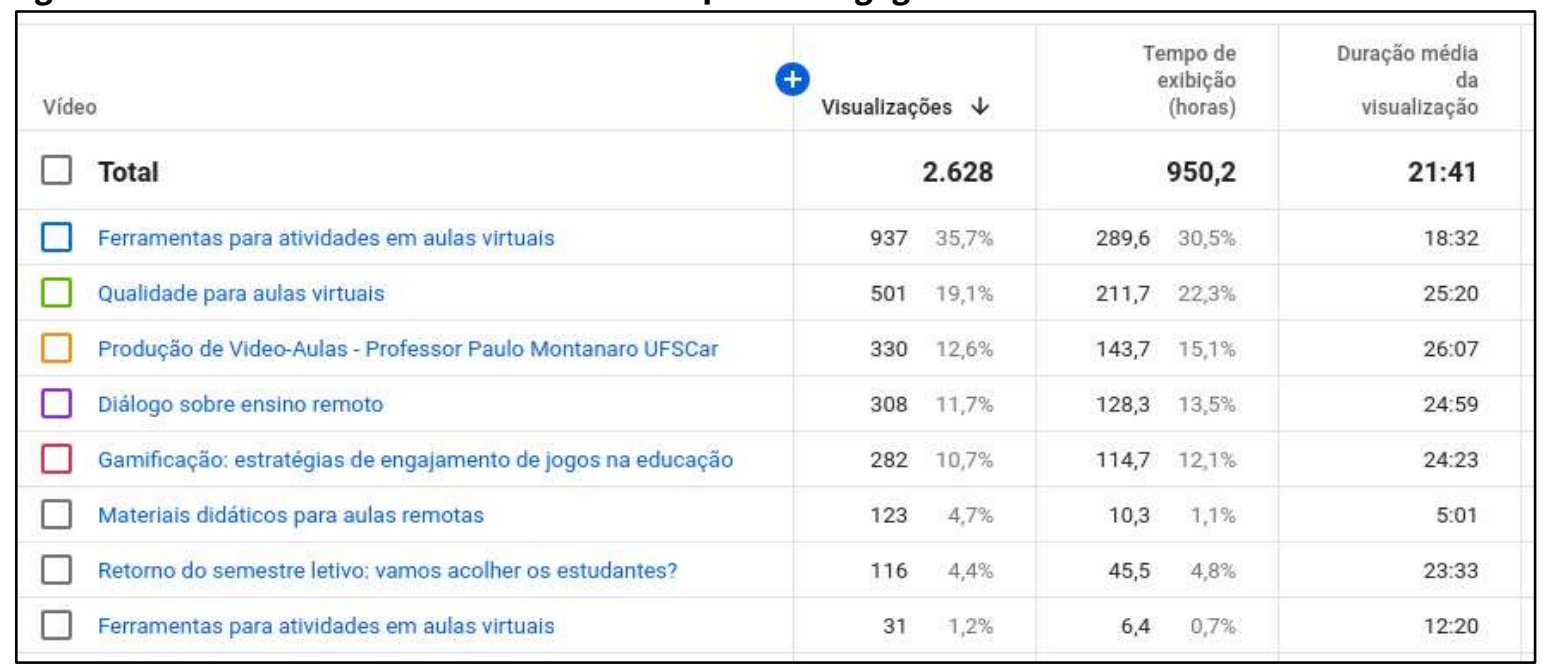

Fonte: YouTube (2020).

Como é possível perceber a partir da análise da Figura 1, alguns vídeos tiveram muito destaque, outros nem tanto. A formação que apresentou ferramentas para aulas virtuais e aquela que tratou da qualidade para aulas virtuais foram as mais acessadas. No total, houve 2.608 visualizações nas 8 transmissões realizadas. O YouTube apresenta várias métricas, entre as quais está a idade do telespectador. 
Figura 2 - Idade dos espectadores do Canal do Núcleo de Apoio Pedagógico

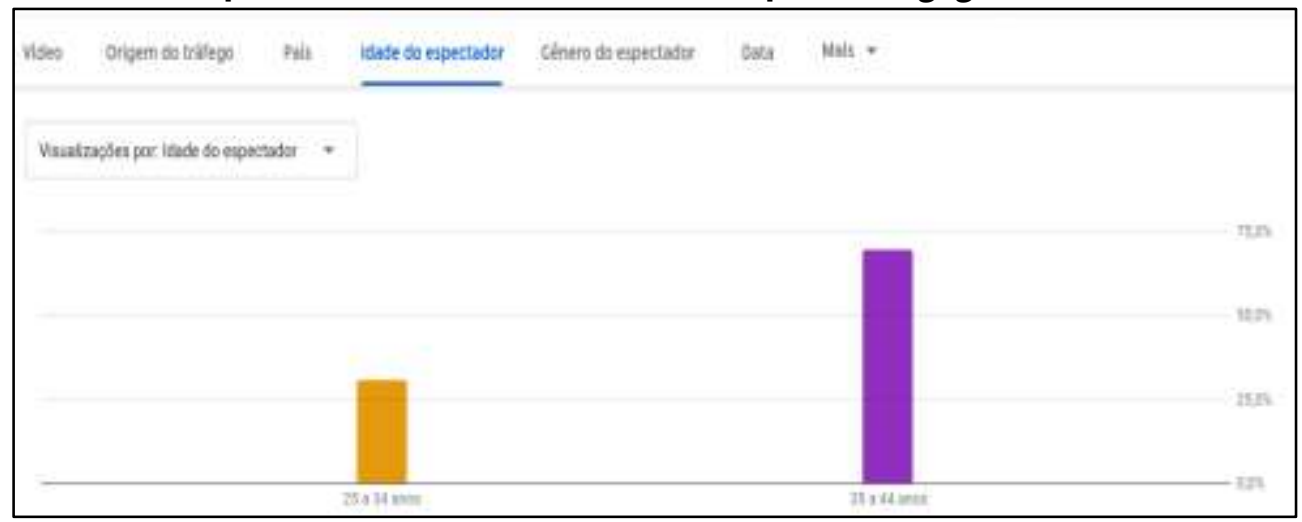

Fonte: YouTube (2020).

A partir da análise da Figura 2, é possível perceber que 60,9\%, ou seja, a maior parte dos espectadores, possuía idade entre 35 e 44 anos. O YouTube realiza a análise da idade do usuário a partir dos dados informados em seu perfil no momento de seu cadastro para criação da conta no Google. Dessa forma, qualquer informação equivocada no momento do cadastro gerará dados que não condizem com a realidade. Além da informação sobre a idade, é possível mapear o gênero do espectador também pelas informações de cadastro. Os dados são apresentados na Figura 3.

Figura 3 - Gênero dos espectadores do Canal do Núcleo de Apoio Pedagógico

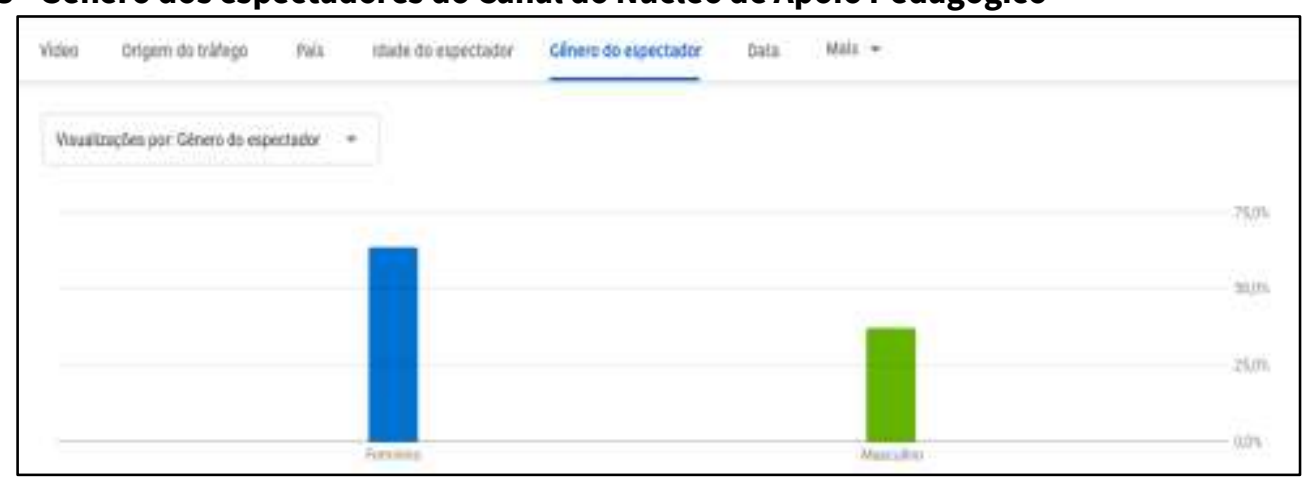

Fonte: YouTube (2020).

Com base nos dados apresentados pela Figura 3, foi possível saber que $63,2 \%$ das pessoas informaram ser do gênero feminino na hora da realização de seu cadastro, esse foi o público mais presente nas formações. Ainda, a partir das estatísticas, pôde-se saber por meio de qual dispositivo as pessoas visualizaram as formações. A Figura 4 apresenta estes dados. 
Figura 4 - Tipo de dispositivo usado pelos espectadores para visualizar os vídeos do Canal do Núcleo de Apoio Pedagógico

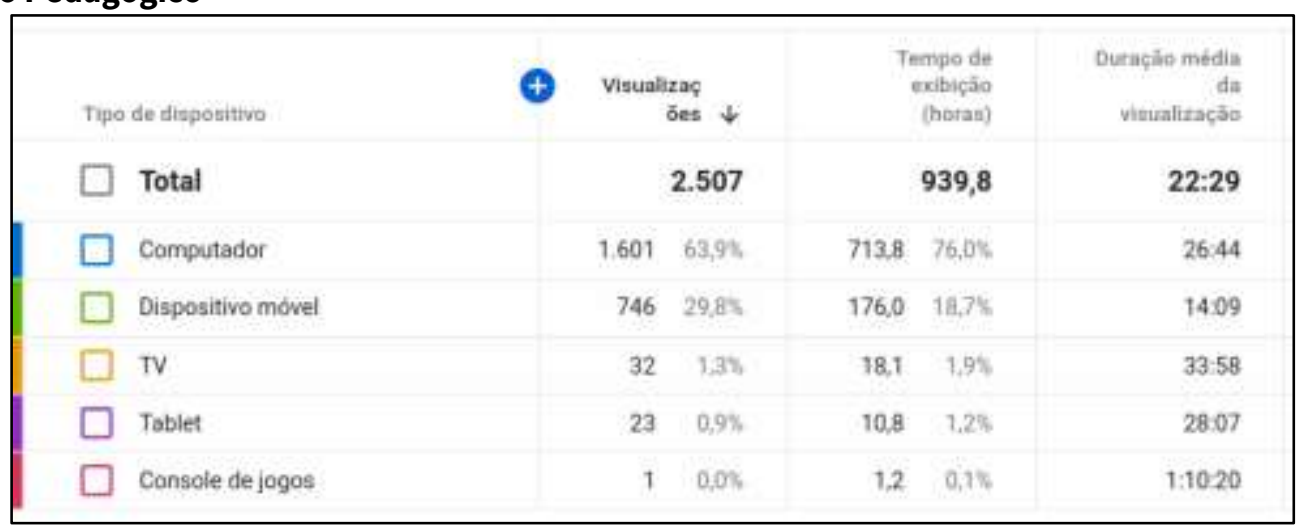

Fonte: YouTube (2020).

Conforme apresentado, o computador foi o meio mais utilizado por todas as pessoas que visualizaram os vídeos publicados no canal do YouTube, ou seja, um percentual de 63,9\% das visualizações foram realizadas a partir desse recurso. 0 dispositivo móvel, provavelmente o celular, foi o segundo dispositivo mais utilizado, com $29,8 \%$ das visualizações.

Por fim, apresenta-se o gráfico que demonstra a origem do acesso à transmissão realizada no YouTube (Figura 5).

Figura 5 - Origem do tráfego ao canal do YouTube

\begin{tabular}{|c|c|c|}
\hline Total & & 815 \\
\hline WhatsApp & 182 & $22,3 \%$ \\
\hline ifrs.edu.br & 169 & $20,7 \%$ \\
\hline webmail.uffs.edu.br & 129 & $15,8 \%$ \\
\hline Facebook & 47 & $5,8 \%$ \\
\hline App do Chrome & 30 & $3,7 \%$ \\
\hline Google Search & 29 & $3,6 \%$ \\
\hline Google & 28 & $3,4 \%$ \\
\hline
\end{tabular}

Fonte: YouTube (2020).

Os dados que demonstram a origem do tráfego, ilustrados na Figura 5, apresentam os meios mais efetivos para divulgação das formações realizadas. De todos os recursos empregados para divulgação, percebe-se que a ferramenta de mensagem instantânea, WhatsApp, e a divulgação realizada pela instituição parceira em duas formações, o IFRS, obtiveram maior alcance. Como não houve parceria externa em todas as formações, destaca-se que o WhatsApp e o e-mail institucional foram os recursos mais eficazes para divulgação.

As formações pedagógicas realizadas pelo NAP do Campus Chapecó até o ano de 2020 foram predominantemente presenciais; no entanto, em função da pandemia do novo coronavírus, as formações foram todas virtuais, cujo resultado contribuiu para maior adesão 
dos participantes. Entre as características positivas dessas formações virtuais destaca-se que: houve maior alcance de pessoas; foi oferecido um ambiente seguro para as capacitações; houve maior oportunidade de interação online com pessoas de outras instituições; aumento da flexibilidade no acesso às formações gravadas, fato que possibilitou que mais pessoas tivessem acesso aos conteúdos trabalhados em datas e horários diversos às transmissões online. Destaca-se também o benefício de contar com profissionais de diferentes instituições federais para ministração das formações sem que houvesse a necessidade de investimento financeiro para deslocamento, ou seja, diárias e passagens.

A experiência com formações virtuais foi muito positiva, pois a partir das transmissões foi possível atingir um universo grande de pessoas e explorar temáticas que possivelmente não seriam abordadas com tanta profundidade se não fosse o Ensino Remoto. Os membros do NAP$\mathrm{CH}$ utilizaram os dados aqui apresentados para avaliar a experiência e planejar as próximas ações pedagógicas. Cabe ressaltar que o apoio pedagógico não é oportunizado apenas por meio de formações, por isso outras ações que visem a contribuir com um acompanhamento pedagógico continuado precisam ser planejadas e instituídas não apenas pelo NAP, mas por todas as instâncias acadêmicas da UFFS.

\section{CONCLUSÃO}

Este artigo apresentou um relato da experiência de implementação do Ensino Remoto no Campus Chapecó da Universidade Federal da Fronteira Sul (UFFS). Entre as principais questões apresentadas, destaca-se o grande envolvimento dos servidores, especialmente professores, nas ações pedagógicas desenvolvidas que buscaram apoiar o planejamento e desenvolvimento das aulas remotas. Como situado logo no início deste relato, a UFFS não possuía o histórico de oferta massiva de cursos ou componentes curriculares no formato semipresencial, o que fez com que a tomada de decisão por aulas no formato remoto fosse uma grande novidade para a maioria dos servidores e estudantes.

Por esse motivo e também pela expectativa de que a pandemia fosse superada já no mês de junho de 2020, a gestão institucional, via Conselho Universitário, preferiu não aderir massivamente ao retorno imediato das aulas mediadas por tecnologias digitais no mês de março. 0 momento pedia cautela nas decisões, pois uma retomada do calendário acadêmico teria impacto não apenas no desenvolvimento do trabalho dos servidores, mas na organização dos estudos dos discentes, muitos dos quais não dispunham de tecnologias para acesso às aulas, fato que foi sanado com o passar do tempo com medidas de inclusão digital próprias da universidade e também advindas do Ministério da Educação.

As ações pedagógicas desenvolvidas contaram com grande número de participantes, como descrito no desenvolvimento deste trabalho. De forma geral, a avaliação foi considerada positiva pelos participantes. Percebeu-se que a urgência nas tomadas de decisões sobre o Ensino Remoto gerou grande insegurança em muitos servidores, fato que demonstra que a UFFS precisa investir em ações de formação, políticas internas e desenvolvimento de equipes para melhor apoiar os processos pedagógicos mediados por tecnologia. 
Esta publicação não teve como objetivo coletar dados junto aos envolvidos com as atividades remotas - professores e estudantes. Dessa forma, sugere-se que estudos futuros possam acompanhar e avaliar os impactos que o Ensino Remoto gerou na rotina, no desempenho acadêmico e no trabalho dos servidores e dos estudantes. Cabe ressaltar que o semestre letivo ainda não havia finalizado quando da conclusão deste estudo, por esse motivo não são apresentados elementos ligados à experiência de professores e estudantes no Ensino Remoto ofertado na UFFS. Medidas que visem a acompanhar a implementação de componentes curriculares no formato semipresencial podem mensurar se as ações desenvolvidas para instituir o Ensino Remoto em 2020 tiveram impacto na formação dos professores e em suas construções de aulas mediadas por tecnologias digitais. Será possível, ainda, acompanhar as alterações nos projetos pedagógicos dos cursos para identificar se aumentará a oferta de componentes curriculares com carga horária semipresencial.

Por fim, cabe ressaltar que o cenário de mudanças emergentes ganha destaque, também, uma significativa ruptura tanto sobre a organização institucional, no que tange aos processos formativos e fornecimento de suporte técnico e pedagógico, quanto nos modos de organizar os processos educativos, sejam eles em sala de aula presencial ou não, uma vez que o uso das tecnologias da informação e das diferentes mídias disponíveis pode se mostrar como um acréscimo na qualidade do ensino ofertado, mesmo que em cursos eminentemente presenciais.

\section{REFERÊNCIAS}

BRASIL. Lei n 12.029 , de 15 de setembro de 2009. Dispõe sobre a criação da Universidade Federal da Fronteira Sul - UFFS e dá outras providências. Diário Oficial da União: seção 1, Brasília, DF, p. 1, 16 set. 2009. Disponível em: http://www.planalto.gov.br/ccivil_03/_ato2007-2010/2009/lei/l12029.htm. Acesso em: 8 jan. 2021.

BRASIL. Portaria $\mathrm{n}^{\circ}$ 4.059, de 10 de Dezembro de 2004. Disposta pelo MEC, regulamenta modalidade semipresencial: portaria 4059. Diário Oficial da União: seção 1, Brasília, DF, p. 34, 13 dez. 2004. Disponível em: http://portal.mec.gov.br/sesu/arquivos/pdf/nova/acs_portaria4059.pdf. Acesso em: 8 jan. 2021.

BRASIL. Portaria $n^{\circ} 2.117$, de 06 de Dezembro de 2019. Dispõe sobre a oferta de carga horária na modalidade de Ensino a Distância - EaD em cursos de graduação presenciais ofertados por Instituições de Educação Superior - IES pertencentes ao Sistema Federal de Ensino. Diário Oficial da União: seção 1, Brasília, DF, n. 239, p. 131, 11 dez. 2019. Disponível em: https://www.in.gov.br/en/web/dou/-/portaria-n2.117-de-6-de-dezembro-de-2019-232670913. Acesso em: 8 jan. 2021.

BRASIL. Portaria n 343, de 17 de Março de 2020. Dispõe sobre a substituição das aulas presenciais por aulas em meios digitais enquanto durar a situação de pandemia do Novo Coronavírus - COVID-19. Diário Oficial da União: seção 1, Brasília, DF, p. 39, 18 mar. 2020a. Disponível em: http://www.planalto.gov.br/CCIVil_03/Portaria/PRT/Portaria\%20n\%C2\%BA\%20343-20-mec.htm. Acesso em: 8 jan. 2021.

BRASIL. Portaria $n^{\circ}$ 544, de 16 de Junho de 2020. Dispõe sobre a substituição das aulas presenciais por aulas em meios digitais, enquanto durar a situação de pandemia do novo coronavírus - Covid-19, e revoga as Portarias MEC $n^{\circ} 343$, de 17 de março de 2020, $n^{\circ} 345$, de 19 de março de 2020, e $n^{\circ} 473$, de 12 de maio de 2020. Diário Oficial da União: seção 1, Brasília, DF, n. 114, p. 62, 17 jun. 2020b. Disponível em: 
https://www.in.gov.br/en/web/dou/-/portaria-n-544-de-16-de-junho-de-2020-261924872. Acesso em: 8 jan. 2021.

BRASIL. Ministério da Educação. Conselho Nacional de Educação. Parecer nº 05, de 28 de abril de 2020. Dispõe sobre a reorganização do Calendário Escolar e da possibilidade de cômputo de atividades não presenciais para fins de cumprimento da carga horária mínima anual, em razão da Pandemia da COVID19. Diário Oficial da União: seção 1, Brasília, DF, n. 83, p. 63, 04 mai. 2020c. Disponível em: http://portal.mec.gov.br/index.php?option=com_docman\&view=download\&alias=14511-pcp00520\&category_slud=marco-2020-pdf\&Itemid=30192. Acesso em: 19 mar. 2021.

UNIVERSIDADE FEDERAL DA FRONTEIRA SUL (UFFS). Conselho Universitário. Resolução n 13/2013, de $\mathbf{2 1}$ de outubro de 2013. Institui o Núcleo de Apoio Pedagógico (NAP) da UFFS. Chapecó: Conselho Universitário, 2013. Disponível em: https://www.uffs.edu.br/atosnormativos/resolucao/consunicgrad/2013-0013. Acesso em: 8 jan. 2021.

UNIVERSIDADE FEDERAL DA FRONTEIRA SUL (UFFS). Conselho Universitário. Resolução n 05/2014, de 26 de junho de 2014. Dispõe sobre a oferta de componentes curriculares ministrados no formato semipresencial nos cursos de graduação presenciais da UFFS. Chapecó: Conselho Universitário, 2014. Disponível em: https://www.uffs.edu.br/atos-normativos/resolucao/consunicgrad/2014-0005. Acesso em: 8 jan. 2021. 